\title{
De Quervain subacute thyroiditis
}

\author{
George Mundy-Baird MBChB, Angelos Kyriacou MBChB MA, Akheel A. Syed MBBS PhD
}

Cite as: CMAJ 2021 July 5;193:E1007. doi: 10.1503/cmaj.202787

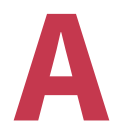
41-year-old woman presented to hospital with anterior neck swelling and pain, made worse with swallowing, after a week of febrile upper respiratory illness. She had an exquisitely tender goitre and fine hand tremor. Her temperature was $37.1^{\circ} \mathrm{C}$, with a resting heart rate of 92-122 beats/minute and blood pressure of $116 / 68 \mathrm{~mm} \mathrm{Hg}$. Her thyroid-stimulating hormone was undetectable at $<0.01$ (normal range 0.35-5.50) $\mathrm{mU} / \mathrm{L}$, with elevated free thyroxine $(59.0 \mathrm{pmol} / \mathrm{L}$; normal range 10.0-20.0), and free triiodothyronine (27.4 pmol/L; normal range 3.5-6.5). Her C-reactive protein and erythrocyte sedimentation rate were also elevated (Appendix 1, available at www.cmaj. ca/lookup/doi/10.1503/cmaj.202787/tab-related -content). The emergency physicians excluded suppurative thyroiditis and thyroid abscess by computed tomography (CT), which showed thyroid enlargement (Figure 1). An endocrinologist diagnosed subacute thyroiditis and prescribed a short course of oral prednisolone, ibuprofen and propranolol; the patient's pain and goitre size reduced within 24 hours. After discharge from hospital, her symptoms resolved without further intervention, followed by a period of asymptomatic hypothyroxinaemia, eventually returning to euthyroidism (Appendix 1).

De Quervain subacute granulomatous thyroiditis, the commonest cause of thyroidal pain, can result from viral infection, ${ }^{1,2}$ including COVID-19. ${ }^{3}$ Diagnosed clinically by history, examination and blood tests, it is usually self-limiting. The classic triphasic pattern starts with an initial thyrotoxicosis lasting 3-6 weeks when preformed thyroid hormones are released due to thyroid-cellular destruction. An intermediate hypothyroid phase of up to 6 months follows, because thyroid hormone stores are depleted. Of patients with the condition, $85 \%-95 \%$ return to their baseline thyroid functioning within 12 months.

Thyroid imaging and biopsy are not usually required, but given the patient's substantially raised inflammatory markers and intense pain, the emergency physicians were concerned about the possibility of suppurative thyroiditis or abscess and therefore ordered a CT scan. Other causes of painful thyroid conditions such as intrathyroidal hemorrhage, cysts, nodules or, rarely, infiltrative cancers were also excluded. Ultrasonography is usually preferred for imaging of the thyroid as it has superior spatial resolution; in painful subacute thyroiditis, the gland is hypoechoic and has low-to-normal vascularity on colour-flow Doppler ultrasonography. ${ }^{1}$ Symptomatic treatment in the acute phase is with $\beta$-blockers for thyrotoxic symptoms (antithyroid medications are ineffective) and nonsteroidal anti-
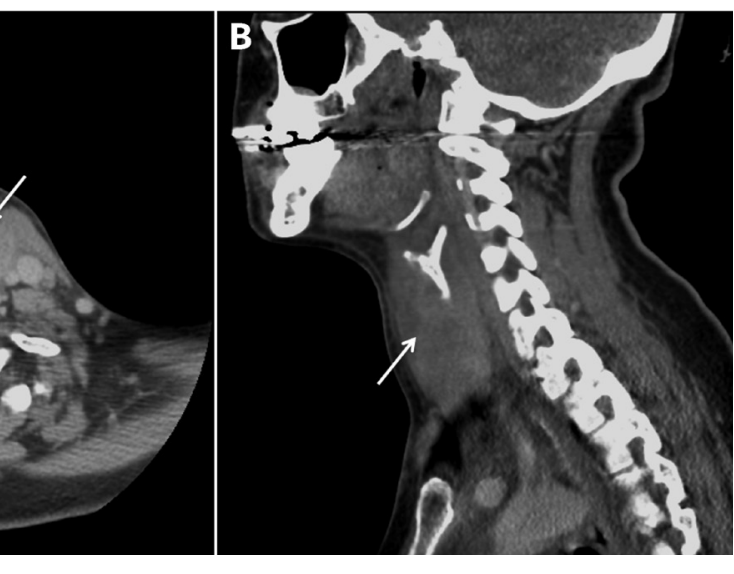

Figure 1: Computed tomography scan of the neck of a 41-year-old woman, performed to exclude acute suppurative thyroiditis or abscess, showing diffusely swollen thyroid gland (arrows) with heterogeneous attenuation characteristic of thyroiditis in transverse (A) and

inflammatory drugs for pain and inflammation. Corticosteroids are recommended for refractory or severe pain and thyrotoxic symptoms. ${ }^{2}$ Levothyroxine may be required in the hypothyroid phase but should be withdrawn after 3-6 months, and long-term treatment continued only if hypothyroidism persists.

\section{References}

1. Pearce EN, Farwell AP, Braverman LE. Thyroiditis. N Engl J Med 2003;348:2646-55.

2. Ross DS, Burch HB, Cooper DS, et al. 2016 American Thyroid Association guidelines for diagnosis and management of hyperthyroidism and other causes of thyrotoxicosis. Thyroid 2016;26:1343-421.

3. Muller I, Cannavaro D, Dazzi D, et al. SARS-CoV-2-related atypical thyroiditis. Lancet Diabetes Endocrinol 2020;8:739-41.

\section{Competing interests: None declared.}

This article has been peer reviewed.

The authors have obtained patient consent.

Affiliations: Department of Endocrinology (Mundy-Baird, Kyriacou, Syed), Salford Royal NHS Foundation Trust \& University Teaching Hospital, Salford, UK; CEDM Centre of Endocrinology Diabetes and Metabolism (Kyriacou), Limassol, Cyprus; Faculty of Biology, Medicine and Health (Syed), The University of Manchester, Manchester, UK

Content licence: This is an Open Access article distributed in accordance with the terms of the Creative Commons Attribution (CC BYNC-ND 4.0) licence, which permits use, distribution and reproduction in any medium, provided that the original publication is properly cited, the use is noncommercial (i.e., research or educational use), and no modifications or adaptations are made. See: https://creativecommons.org/licenses/by-nc-nd/4.0/

Correspondence to: Akheel Syed, akheel.syed@manchester.ac.uk 